\title{
Early incidence of deep venous thrombosis and its risk factors after knee arthroscopic surgery in patients with anticoagulant and non-anticoagulant
}

\section{Lei Shu}

Wuhan University Zhongnan Hospital

Qubo Ni

Wuhan University Zhongnan Hospital

Biao Chen

Wuhan University Zhongnan Hospital

Hangyuan He

Wuhan University Zhongnan Hospital

Liaobin Chen ( $\square$ lbchen@whu.edu.cn )

Wuhan University Zhongnan Hospital

Xu Yang

Wuhan University Zhongnan Hospital

Research article

Keywords: Arthroscopic knee surgery, Deep venous thrombosis, D-dimer, Low molecular weight heparin, Postoperative complications

Posted Date: July 29th, 2020

DOl: https://doi.org/10.21203/rs.3.rs-44143/v1

License: (9) This work is licensed under a Creative Commons Attribution 4.0 International License.

Read Full License 


\section{Abstract}

Purpose: To investigated the early incidence of deep venous thrombosis (DVT) and its risk factors after knee arthroscopic surgery in patients with anticoagulant and non-anticoagulant.

Methods: 272 patients were reviewed who have undergone knee arthroscopic surgery in our hospital from January 2018 to October 2019. Color doppler ultrasound was performed for every patient at $24 \mathrm{~h}$ preoperatively and three days after operation. On the first day after surgery, low molecular weight heparin $(\mathrm{LMWH})$ was randomly administered to some patients and not in others. The following factors were recorded: gender, age, body mass index (BMI), preoperative platelet and D-dimer level, D-dimer level three days after surgery, anesthetic technique, tourniquet time, whether to use LMWH after operation, and type of surgical procedures. Chi-square test or Student $t$ test was used to preliminarily screen out suspected risk factors. Then, multiple logistic regression analysis was utilized to further determine the risk factors of DVT after knee arthroscopic surgery.

Results: The incidence of DVT in the postoperative anticoagulant group was $7.5 \%$, and $7.4 \%$ in the nonanticoagulant group. An increased incidence was found among higher D-dimer level postoperatively. There was no significant difference in the incidence of DVT between use of LMWH and non-use of LMWH in three days after surgery.

Conclusion: The early incidence of DVT in the group of patients without LMWH was 7.4\%. The incidence of DVT in patients with knee arthroscopy surgery could not be reduced by using LMWH within three days, and high D-dimer level was a risk factor for DVT after knee arthroscopic surgery.

\section{Introduction}

With the improvement of arthroscopy technology, more and more therapeutic operations can be performed under arthroscopy [1]. However, the incidence of deep vein thrombosis (DVT) after arthroscopy surgery has also increased due to the improved accuracy of thrombosis diagnosis, which has caused concerns of orthopedic surgeons. The incidence has been reported between 1.8-41.2\% [2], and in patients undergoing high-energy knee trauma, the incidence of preoperative DVT was as high as 50\% [3]. The study of Bohensky et al. [4] showed that DVT had become the most common complication after arthroscopic surgery. But even worse, DVT may occasionally developed into a fatal complication: pulmonary embolism (PE) $[5,6]$. Currently, there is still a big debate about whether prophylaxis should be a criterion after arthroscopic surgery. For instance, the American College of Chest Physicians indicated that it is not recommended to use thrombosis prevention measures for patients unless risk factors are present [7]. Several studies suggested that gender, age, BMI and other factors may be the potential risk factors of DVT [8-12]. Based on evidence existed, our purpose is to study the incidence of DVT in the two groups of anticoagulation and non-anticoagulation patients, as well as the risk factors of DVT formation after knee arthroscopic surgery. 


\section{Materials And Methods \\ Patients}

A retrospective analysis was performed on 272 patients who have underwent arthroscopic surgery in our hospital from January 2018 to October 2019. Surgeries were divided into two categories, simple (including meniscectomy, meniscus suture, loose body removal, cartilage cleanup, or cystectomy) and ligament reconstruction [anterior cruciate ligament reconstruction (ACLR), posterior cruciate ligament reconstruction (PCLR), or ACLR combined with PCLR]. Preoperatively, patients were excluded from pregnancy, with DVT, previous history of DVT, varicose veins or blood system diseases, taking anticoagulant drugs within half a year, or with complicated periarticular fractures. This study was approved by our hospital's ethics committee, and written informed consent was obtained from all participants.

\section{Operative Procedure}

The choice of anesthesia was determined by patient and anesthesiologist, and the procedure was performed by two experienced surgeons. Tourniquet time was routinely set for 90 minutes, if the time needed to be extended, the tourniquet would be inflated for 10 minutes and refilled again. All tendons used in ligament reconstruction surgeries were autografts. After the operation, ice was routinely applied to the wound until the third day. 24 hours later, the patients begun to do some exercise like isometric contraction of the quadriceps, and no other physical preventive measures were taken. All patients were not given drugs to prevent thrombosis before surgery, but the patients were randomly divided into two groups on the first day after surgery, one group was injected subcutaneously with low molecular weight heparin (LMWH, enoxaparin, $0.2 \mathrm{ml}$ ) once a day, and another group was not.

\section{Diagnosis of DVT}

All patients underwent color doppler arteriovenous ultrasound of the lower extremities within 24 hours preoperatively and on the third day postoperatively to determine whether thrombosis was existed, and all patients were operated by the same ultrasound doctor and diagnosed by another doctor. The specific diagnostic criteria [13] are as follows: hypoechoic masses appear in venous vein, or venous vein cannot be compressed, or venous blood flow was absent. DVT was classified as proximal DVT (occurred in popliteal vein and above) and distal DVT (occurred in deep vein below the knee joint plane). As long as

the patient had symptoms such as local pain and obvious swelling in the lower extremities, an ultrasound examination was performed immediately to determine whether DVT was formed. When patients had chest pain, dyspnea, decreased oxygen saturation and other PE symptoms, computed tomographic pulmonary angiography (CTPA) should be performed instantly to determine whether PE occurred. Once diagnosed with DVT or PE, the patients rested in bed strictly and received relevant treatment based on the consultation of the thoracic and cardiovascular surgeon.

\section{Statistical analysis}


Each patient underwent a routine preoperative examination after admission and the following factors were recorded: gender, age, body mass index (BMI), preoperative platelet and D-dimer level, D-dimer level three days after surgery, anesthetic technique, tourniquet time, whether to use LMWH after surgery, and type of surgical procedures. All patients were categorized into two subgroups according to the occurrence and absence of DVT. SPSS 22.0 (IBM Corp. Released 2013. IBM SPSS Statistics for Windows. Armonk, NY: IBM Corp) software was used for statistical analysis. Using Chi-square test or Student $t$ test for the comparison of data, so as to preliminarily screen out suspected risk factors. Then multiple logistic regression analysis was utilized to further determine the risk factors $(P<0.05$ was considered statistically significant).

\section{Results}

A total of 272 patients underwent knee arthroscopic surgery were enrolled in this study, and postoperative ultrasound examination of lower extremity veins showed that 21 (7.7\%) of them had DVT, two of which were identified as symptomatic thrombosis. The incidence of DVT in the postoperative anticoagulant group was $7.5 \%[14 /(14+163)]$, which in the non-anticoagulant group was $7.4 \%[7 /(7+88)]$. The locations of the thrombosis is shown in Table 1, DVT mainly occurred in the distal extremity of the lower limbs $(90.5 \%, 19 / 21)$, among which the thrombosis in the muscular vein was the most common. No serious complications such as PE occurred, and no patients died due to PE or DVT. 
Table 1

Distribution of DVT

\begin{tabular}{|ll|}
\hline Location & Number \\
\hline Proximal DVT & 3 \\
\hline Iliac & 0 \\
\hline Femoral & 0 \\
\hline Popliteal & 3 \\
\hline Distal DVT & 18 \\
\hline Muscular & 9 \\
\hline Peroneal & 1 \\
\hline Anterior tibial & 1 \\
\hline Posterior tibial & 5 \\
\hline Muscular + Peroneal & 1 \\
\hline Muscular + Anterior tibial & 0 \\
\hline Muscular + Posterior tibial & 1 \\
\hline Anterior tibial + Posterior tibial + Peroneal & 0 \\
\hline Total & 21 \\
\hline DVT, deep venous thrombosis. & \\
\hline & \\
\hline
\end{tabular}

The patients were divided in two groups according to whether postoperative DVT occurred. The distribution of DVT occurred in each observation factor is shown in Table 2. There was no statistically significant difference between the two groups in age, gender, BMI, preoperative D-dimer and platelet counts, anesthetic technique and whether LMWH was used after surgery $(p>0.05)$, but was significant in the $\mathrm{D}$-dimer level three days after surgery, duration of tourniquet application and surgical procedures, which were considered as potential risk factors $(p<0.05)$. 
Table 2

Clinical risk factors associated with DVT

\begin{tabular}{|lllll|}
\hline Parameters & DVT $(-)$ & DVT (+) & $t / \mathbf{x}^{2}$ & P \\
\hline Age (year) & $40.2 \pm 17.4$ & $40.0 \pm 14.5$ & $t=-0.043$ & .966 \\
\hline Sex (male/female) & $143 / 108$ & $13 / 8$ & $x^{2}=0.019$ & .661 \\
\hline BMI (Kg/m $\left.{ }^{2}\right)$ & $23.7 \pm 3.7$ & $24.0 \pm 4.2$ & $t=-0.342$ & .732 \\
\hline DD (mg/L) preoperative & $0.1 \pm 0.2$ & $0.2 \pm 0.3$ & $t=-1.542$ & .124 \\
\hline DD (mg/L) postoperative & $0.3 \pm 0.4$ & $0.8 \pm 0.8$ & $t=-2.752$ & .012 \\
\hline PLT (x 109/L) preoperative & $220.9 \pm 57.9$ & $196.8 \pm 47.3$ & $t=1.859$ & .064 \\
\hline Anesthesia type (general/spinel) & $52 / 199$ & $5 / 16$ & $x^{2}=0.112$ & .738 \\
\hline Use of LMWH & $163 / 88$ & $14 / 7$ & $x^{2}=0.025$ & .873 \\
\hline Tourniquet time (min) & $123.9 \pm 59.6$ & $158.1 \pm 64.3$ & $t=-2.511$ & .013 \\
\hline Surgery type (simple/ligament reconstruction) & $160 / 91$ & $7 / 14$ & $x^{2}=7.562$ & .006 \\
\hline $\begin{array}{l}\text { DVT, deep venous thrombosis; BMl, Body Mass Index; DD, D-dimer; PLT, platelet; } \text { LMWH, low molecular } \\
\text { weight heparin. }\end{array}$ & & & & \\
\hline
\end{tabular}

The results of multivariate regression analysis of DVT group and non-DVT group patients are shown in Table 3. The results indicated that only postoperative D-dimer was an independent risk factor for predicting early DVT formation after knee arthroscopy $(\mathrm{OR}=3.773,95 \% \mathrm{Cl}: 1.775-8.023, \chi 2=11.906, \mathrm{P}=$ $0.001)$, and the operation method and tourniquet time are not related risk factors. 
Table 3

The results of multivariate regression analysis of risk factors in DVT

\begin{tabular}{|c|c|c|c|c|}
\hline Risk factors & OR & $95 \% \mathrm{Cl}$ & $x^{2}$ & $P$ \\
\hline $\mathrm{DD}(\mathrm{mg} / \mathrm{L})$ postoperative & 3.7 & $1.8-8.0$ & 11.906 & .001 \\
\hline \multicolumn{5}{|l|}{ Tourniquet time(min) } \\
\hline \multicolumn{5}{|l|}{ \60* } \\
\hline $60-120$ & $>10000$ & - & 0.000 & .998 \\
\hline$\bigotimes 120$ & $>10000$ & - & 0.000 & .998 \\
\hline \multicolumn{5}{|c|}{ Surgery type(simple/ligament reconstruction) } \\
\hline \multicolumn{5}{|l|}{ Simple* } \\
\hline ACLR & 1.8 & $0.4-7.5$ & 0.707 & .401 \\
\hline PCLR & 1.3 & $0.1-15.2$ & 0.400 & .842 \\
\hline$A C L R+P C L R$ & 1.0 & $0.1-7.3$ & 0.000 & .985 \\
\hline \multicolumn{5}{|c|}{$\begin{array}{l}\text { DVT, deep venous thrombosis; OR, odds ratio; } \mathrm{Cl} \text {, confidence interval; } \mathrm{DD}, \mathrm{D}-\mathrm{dimer} ; \mathrm{ACLR} \text {, anterior } \\
\text { cruciate ligament reconstruction; } \mathrm{PCLR} \text {, posterior cruciate ligament reconstruction. }\end{array}$} \\
\hline
\end{tabular}

\section{Discussion}

This study showed that for knee arthroscopy surgery, the incidence of DVT in patients without anticoagulation was $7.4 \%$, which is very close to the result of Delis et al. [14], although the incidence was not as high as major operations such as arthroplasty [15], but its importance cannot be ignored. In contrast, the incidence of DVT in the anticoagulation patients group was $7.5 \%$, which indicated that the use of LMWH may not reduce the probability of DVT in patients within three days after knee arthroscopic surgery. Kessler [16] noted that it is suitable to use LMWH for five to seven days after arthroscopic knee surgery. Another randomized controlled trial has revealed that prophylaxis should last seven to ten days [17], as other studies have shown poor results for short-term preventive treatment of only three to six days $[18,19]$. Although LMWH did not increase the risk of perioperative bleeding, it was not a protective factor to prevent the formation of postoperative DVT in three days. In some previous studies, it was shown that thromboprophylaxis was not recommended after arthroscopic surgery [20-22]. A recent systematic review suggested that they against routine use of thromboprophylaxis even after anterior cruciate ligament reconstruction surgery [23]. In arthroplasty operations, the use of LMWH has become an industry guideline [24], however, among patients undergoing arthroscopic surgery, a short-term use of LMWH is not recommended to prevent the formation of DVT in patients without risk factors according to 
D-dimer as a fibrin degradation product, generally assumed has a tendency to decline to normal level within three to ten days after tissue injury $[25,26]$, and has a high sensitivity for predicting the formation of postoperative DVT [27]. Although D-dimer is affected by pregnancy, trauma, tumor and surgery [28, 29], this study excluded possible influencing factors except for surgery, we tried our best to minimize its effects. D-dimer is a sensitive but non-specific marker of DVT, so the positive result of D-dimer cannot be used for diagnosis, on the contrary, the possibility of thrombosis can be excluded when D- dimer is negative [30,31]. Our results also demonstrated that for every unit increase in D-dimer, the probability of patients suffering from DVT increased by 3.7 times, so anticoagulation is necessary for patients with high D-dimer after knee arthroscopic surgery. Meanwhile, D-dimer provides a characteristic of quick and convenient. It can also be used as a routine examination to screen the formation of DVT in hospitals without ultrasound or venography, and unnecessary examination can be avoided for some low-risk patients.

The incidence of non-symptomatic DVT is very high (19/21,90.5\%), which was similar to those of sun et al. [32], so adequate attention should be paid to the latent DVT, and it is not reliable to diagnose the occurrence of DVT solely by clinical symptoms. At present, there are more and more diagnostic measures for thrombosis. Color doppler ultrasound as the preferred detection method has the advantages of quickness, convenience, non-invasiveness, and radiation-free, and has relatively high sensitivity and accuracy [33-35]. In this study, a high incidence of DVT was detected by color doppler ultrasound 3 days after surgery. Therefore, it is suggested that early ultrasound examination is necessary for each patient with increased D-dimer level after knee arthroscopic surgery.

\section{Limitations}

Our research still has some limitations. First of all, this study was limited to the early assessment of the incidence of DVT after surgery in patients with knee arthroscopic surgery, and there was no continuous monitoring of the occurrence of subsequent thrombosis in patients. Some patients may develop DVT after discharge, which probably underestimate the incidence of DVT. Secondly, although doppler ultrasound has been used as the main monitoring method for DVT, venography is still the gold standard $[30,36]$, which may also reduce the incidence of DVT in this research. Furthermore, this research was a retrospective study with a limited sample size, which cannot fully incorporate the risk factors that may affect the formation of DVT. Therefore, the conclusions of this study need to be further verified by a larger sample size and multi-center randomized controlled study. Finally, although D-dimer was a risk factor for postoperative DVT in patients with knee arthroscopic surgery, this study did not point out that the threshold for D-dimer to predict the occurrence of DVT, which may be the study we need to carry out in the later stage.

\section{Conclusion}

To conclude the early incidence of DVT in the group of patients without LMWH was $7.45 \%$. The incidence 
postoperatively, and high D-dimer level was a risk factor for DVT after knee arthroscopic surgery.

Therefore, attention should be paid to these patients and individualized anticoagulant therapy should be given appropriately.

\section{Abbreviations}

ACLR: anterior cruciate ligament reconstruction

BMI: Body Mass Index

Cl: confidence interval

CTPA: computed tomographic pulmonary angiography

DVT: deep venous thrombosis

DD: D-dimer

LMWH: low molecular weight heparin

OR: odds ratio

PE: pulmonary embolism

PCLR: posterior cruciate ligament reconstruction

\section{Declarations}

\section{Acknowledgements}

The authors thank all the participants and instructors who participated in the study.

\section{Authors' contributions}

This study was projected by CLB and YX. The first draft of the manuscript was written by SL. All authors (SL, NQB, CB, HHY, CLB, YX ) contributed to interpretation of the results and revision of the manuscript. All authors have approved the manuscript before submission.

\section{Funding}

This research was financially sponsored by the "National Natural Science Foundation of China (81972036)" and the "National Natural Science Foundation of China (81673490)" directed by Prof. Liaobin Chen. Both foundations play important roles in the design and analysis, especially the collection of the data. 
Availability of data and materials

All data are included in the manuscript.

\section{Ethics approval and consent to participate}

The Ethics Committee of Wuhan University Affiliated Zhongnan Hospital concluded that no approval is necessary for study based on its retrospective design. All patients agreed to the use of data in the study by oral consent. The oral consent approval was documented in the patients' files, which was approved by the Ethics Committee of Wuhan University Affiliated Zhongnan Hospital. All clinical investigations were conducted in accordance with the guidelines of the Declaration of Helsinki.

Consent for publication

Not applicable.

Competing interests

The authors declare no competing interests associated with this manuscript.

Author details

Department of Orthopedic Surgery, Zhongnan Hospital of Wuhan University, Wuhan 430071, China.

\section{References}

1. Kim S, Bosque J, Meehan JP, Jamali A, Marder R: Increase in outpatient knee arthroscopy in the United States: a comparison of National Surveys of Ambulatory Surgery, 1996 and 2006. J Bone Joint Surg Am 2011, 93(11).

2. Sun Y, Chen D, Xu Z, Shi D, Dai J, Qin J, Qin J, Jiang Q: Deep venous thrombosis after knee arthroscopy: a systematic review and meta-analysis. Arthroscopy 2014, 30(3):406-412.

3. Rong Z, Yao Y, Chen D, Song K, Zheng M, Jiang Q: The incidence of deep venous thrombosis before arthroscopy among patients suffering from high-energy knee trauma. Knee Surg Sports Traumatol Arthrosc 2016, 24(5):1717-1721.

4. Bohensky MA, deSteiger R, Kondogiannis C, Sundararajan V, Andrianopoulos N, Bucknill A, McColl G, Brand CA: Adverse outcomes associated with elective knee arthroscopy: a population-based cohort study. Arthroscopy 2013, 29(4):716-725.

5. Takigami J, Hashimoto Y, Yamasaki S, Terai S, Nakamura H: A case of asymptomatic bilateral massive pulmonary embolism after arthroscopic multiple knee ligament reconstruction. Knee Surg Sports Traumatol Arthrosc 2017, 25(1):260-262.

6. Fang $\mathrm{C}-\mathrm{H}$, Liu H, Zhang J-H, Yan S-G: An unusual case of symptomatic deep vein thrombosis and nulmonarv embolism after arthrosconnic, meniscus surgery. BMC Musculoskelet Disord 2018, 
19(1):19.

7. Falck-Ytter Y, Francis CW, Johanson NA, Curley C, Dahl OE, Schulman S, Ortel TL, Pauker SG, Colwell CW: Prevention of VTE in orthopedic surgery patients: Antithrombotic Therapy and Prevention of Thrombosis, 9th ed: American College of Chest Physicians Evidence-Based Clinical Practice Guidelines. Chest 2012, 141(2 Suppl):e278S-e325S.

8. Bulger CM, Jacobs C, Patel NH: Epidemiology of acute deep vein thrombosis. Tech Vasc Interv Radiol 2004, 7(2):50-54.

9. Nurmohamed MT, Büller HR, ten Cate JW: Physiological changes due to age. Implications for the prevention and treatment of thrombosis in older patients. Drugs Aging 1994, 5(1):20-33.

10. Krych AJ, Sousa PL, Morgan JA, Levy BA, Stuart MJ, Dahm DL: Incidence and Risk Factor Analysis of Symptomatic Venous Thromboembolism After Knee Arthroscopy. Arthroscopy 2015, 31(11):21122118.

11. Bokshan SL, DeFroda SF, Panarello NM, Owens BD: Risk Factors for Deep Vein Thrombosis or Pulmonary Embolus Following Anterior Cruciate Ligament Reconstruction. Orthop J Sports Med 2018, 6(6):2325967118781328.

12. Martin CT, Pugely AJ, Gao Y, Wolf BR: Risk factors for thirty-day morbidity and mortality following knee arthroscopy: a review of 12,271 patients from the national surgical quality improvement program database. J Bone Joint Surg Am 2013, 95(14):e98 91-e9810.

13. Dauzat M, Laroche JP, Deklunder G, Ayoub J, Quére I, Lopez FM, Janbon C: Diagnosis of acute lower limb deep venous thrombosis with ultrasound: trends and controversies. J Clin Ultrasound 1997, 25(7):343-358.

14. Delis KT, Hunt N, Strachan RK, Nicolaides AN: Incidence, natural history and risk factors of deep vein thrombosis in elective knee arthroscopy. Thromb Haemost 2001, 86(3):817-821.

15. Piovella F, Wang CJ, Lu H, Lee K, Lee LH, Lee WC, Turpie AGG, Gallus AS, Planès A, Passera R et al: Deep-vein thrombosis rates after major orthopedic surgery in Asia. An epidemiological study based on postoperative screening with centrally adjudicated bilateral venography. $J$ Thromb Haemost 2005, 3(12):2664-2670.

16. Kessler P: [Venous thromboembolism prophylaxis in orthopaedics and traumatology]. Vnitr Lek 2009, 55(3):204-210.

17. Wirth T, Schneider B, Misselwitz F, Lomb M, Tüylü H, Egbring R, Griss P: Prevention of venous thromboembolism after knee arthroscopy with low-molecular weight heparin (reviparin): Results of a randomized controlled trial. Arthroscopy 2001, 17(4):393-399.

18. Schain FH: [Prevention of thrombosis with fraxiparin $\mathbf{0 . 3}$ after ambulatory surgery]. Fortschr Med 1996, 114(12):149-152.

19. Schippinger G, Wirnsberger GH, Obernosterer A, Babinski K: Thromboembolic complications after arthroscopic knee surgery. Incidence and risk factors in 101 patients. Acta Orthop Scand 1998, 69(2):144-146. 
20. Cullison TR, Muldoon MP, Gorman JD, Goff WB: The incidence of deep venous thrombosis in anterior cruciate ligament reconstruction. Arthroscopy 1996, 12(6):657-659.

21. Williams JS, Hulstyn MJ, Fadale PD, Lindy PB, Ehrlich MG, Cronan J, Dorfman G: Incidence of deep vein thrombosis after arthroscopic knee surgery: a prospective study. Arthroscopy 1995, 11(6):701705.

22. Adala R, Anand A, Kodikal G: Deep vein thrombosis and thromboprophylaxis in arthroscopic anterior cruciate ligament reconstruction. Indian J Orthop 2011, 45(5):450-453.

23. Kraus Schmitz J, Lindgren V, Janarv PM, Forssblad M, Stålman A: Deep venous thrombosis and pulmonary embolism after anterior cruciate ligament reconstruction: incidence, outcome, and risk factors. Bone Joint J 2019, 101-B(1):34-40.

24. Geerts WH, Pineo GF, Heit JA, Bergqvist D, Lassen MR, Colwell CW, Ray JG: Prevention of venous thromboembolism: the Seventh ACCP Conference on Antithrombotic and Thrombolytic Therapy. Chest 2004, 126(3 Suppl):338S-400S.

25. Enderson BL, Chen JP, Robinson R, Maull Kl: Fibrinolysis in multisystem trauma patients. J Trauma 1991, 31(9):1240-1246.

26. Johna S, Cemaj S, O'Callaghan T, Catalano R: Effect of tissue injury on D-Dimer levels: a prospective study in trauma patients. Med Sci Monit 2002, 8(1):CR5-CR8.

27. Khaira HS, Mann J: Plasma D-dimer measurement in patients with suspected DVT-a means of avoiding unnecessary venography. Eur J Vasc Endovasc Surg 1998, 15(3):235-238.

28. Ho C-H: Can very high level of D-dimer exclusively predict the presence of thromboembolic diseases? J Chin Med Assoc 2011, 74(4):151-154.

29. Mountain D, Jacobs I, Haig A: The VIDAS D-dimer test for venous thromboembolism: a prospective surveillance study shows maintenance of sensitivity and specificity when used in normal clinical practice. Am J Emerg Med 2007, 25(4):464-471.

30. Wells PS: Integrated strategies for the diagnosis of venous thromboembolism. J Thromb Haemost 2007, 5 Suppl 1:41-50.

31. Adam SS, Key NS, Greenberg CS: D-dimer antigen: current concepts and future prospects. Blood 2009, 113(13):2878-2887.

32. Sun Y, Chen D, Xu Z, Shi D, Dai J, Qin J, Jiang Q: Incidence of symptomatic and asymptomatic venous thromboembolism after elective knee arthroscopic surgery: a retrospective study with routinely applied venography. Arthroscopy 2014, 30(7):818-822.

33. Lensing AW, Prandoni P, Brandjes D, Huisman PM, Vigo M, Tomasella G, Krekt J, Wouter Ten Cate J, Huisman MV, Büller HR: Detection of deep-vein thrombosis by real-time B-mode ultrasonography. $N$ Engl J Med 1989, 320(6):342-345.

34. Anand SS, Wells PS, Hunt D, Brill-Edwards P, Cook D, Ginsberg JS: Does this patient have deep vein thrombosis? JAMA 1998, 279(14):1094-1099. 
35. Grady-Benson JC, Oishi CS, Hanson PB, Colwell CW, Otis SM, Walker RH: Postoperative surveillance for deep venous thrombosis with duplex ultrasonography after total knee arthroplasty. $J$ Bone Joint Surg Am 1994, 76(11):1649-1657.

36. Beyer J, Schellong S: Deep vein thrombosis: Current diagnostic strategy. Eur J Intern Med 2005, 16(4):238-246. 